\title{
Studies on the identity of the parasitoids Aphidius colemani and Aphidius transcaspicus (Hymenoptera: Braconidae)
}

\author{
NiKolaos GARANTONAKIS ${ }^{1}$, Dionyssios PERDIKIS ${ }^{1}$, DionysSios LYKOURESSIS ${ }^{1}$, AnNA KOURTI² \\ and THEODOROS GKOUVITSAS ${ }^{2}$ \\ ${ }^{1}$ Laboratory of Agricultural Zoology and Entomology, Agricultural University of Athens, Iera Odos 75, 11855 Athens, Greece; \\ e-mail: dperdikis@aua.gr \\ ${ }^{2}$ Department of Agricultural Biotechnology, Agricultural University of Athens, Iera Odos 75, 118 55, Athens, Greece
}

Key words. Aphidius colemani, Aphidius transcaspicus, Aphidiinae, Braconidae, aphid parasitoids, cross mating, identification, molecular methods

\begin{abstract}
The taxonomic status of the aphid parasitoid Aphidius colemani Viereck has been questioned, especially in regard to Aphidius transcaspicus Telenga (Hymenoptera: Braconidae). The genetic association between A. colemani and A. transcaspicus was studied by cross mating individuals of $A$. colemani and $A$. transcaspicus (A.c. $+\times$ A.t. $\delta$ and A.c. $\hat{\delta} \times$ A.t. + ) and applying appropriate molecular methods. The cross mating resulted in offspring (female and males) that were fertile. Therefore, the cross mating assays performed in an artificial environment showed that these two populations are potentially compatible. The mean number of mummies that developed and the sex ratio of the offspring of each cross were similar. Most of the male and female offspring from each cross were assigned to $A$. transcaspicus. Furthermore, the genetic divergence between the ribosomal internal transcribed spacers (ITS2) of the A. colemani and A. transcaspicus studied was $16 \%$. These results indicate that $A$. colemani might be a complex of species with different morphological and biological characters attacking different host aphids.
\end{abstract}

\section{INTRODUCTION}

In the Aphidiinae, a subfamily of Braconidae, 400 species are described in 60 genera and subgenera (Starý, 1988). Members of this subfamily are endoparasitoids of aphids and include genera in which many species are important biological control agents. The genus Aphidius Nees is the largest genus of aphid parasitoids with about 70 species recorded throughout the world (Pungerl, 1986).

Aphidius colemani Viereck (Hymenoptera: Aphidiinae) is presumed to be a species of Indian origin. Its hosts belong to the family Aphididae (Starý, 1975). It is a polyphagous parasitoid, which is widely used in the biological control of Aphis gossypii (Glover) (Homoptera: Aphididae) and Myzus persicae (Sulzer) infesting protected crops (van Schelt et al., 1990; Grasswitz \& Reese, 1998; Elenberg et al., 2000; Bolckmans \& Tetteroo, 2002; van Lenteren, 2003; Yano, 2006).

Aphidius transcaspicus Telenga (Hymenoptera: Aphidiinae) is recorded as a parasitoid of the following aphid genera Hyalopterus Koch, Melanaphis (Van der Goot) and Rhopalosiphum (Koch) (Starý, 1964, 1966). It is widely distributed throughout the Mediterranean, Asia Minor, Transcaucasia, and central Asia (Starý, 1964). It is an effective natural enemy of Hyalopterus persikonus (= Hyalopterus pruni) (Geoffroy) (Homoptera: Aphididae) on peach, according to Starý (1965) and Lozier et al. (2008a). Recently, it has attracted interest as a potential candidate for use in the biological control of aphids on prunes in California (Mills, 2002).
A. colemani and A. transcaspicus are very similar morphologically and difficult to separate. Starý (1975) considered $A$. colemani as synonymous with $A$. transcaspicus. Rabasse et al. (1985) compared populations of $A$. colemani from southern France and Brazil reared in Melanaphis donacis (Passerini) and Aphis nerii (Boyer), respectively. Their detailed investigation indicates that these populations differed in the number of antennal segments; the females of the population from southern France had 16-17 segments (rarely 15) and those from Brazil 15-16 segments (rarely 14). These populations also differed in their esterase patterns detected by electrophoresis. The $\mathrm{R}^{\mathrm{F}}$ of the population from southern France was 0.80 and that of the Brazil population 0.63 and 0.70 .

Pennacchio (1990) describes A. colemani reared from A. nerii and Hyalopterus spp. The A. colemani females have 15-16 antennal segments and their labial palps are 2 segmented (rarely 3 segmented). Takada (1998) states that Aphidius magdae Meschloff and Rosen (possibly = A. transcaspicus) is a species of Palearctic origin and occurs in Japan and Israel. The antennae of females of $A$. magdae have 16 (rarely 15 or 17) segments and their labial palps are 3 segmented. This species mainly specializes in parasitizing Hyalopterus spp., but has also been reared from Schizaphis rotundiventris (Signoret) and Toxoptera aurantii (Boyer de Fonscolombe). Kavallieratos \& Lykouressis (1999) examined specimens of $A$. transcaspicus that emerged from Hyalopterus spp. and compared them with specimens of $A$. colemani reared from several aphid species in Greece. They report that $A$. transcaspicus females can easily be distinguished from those of $A$. colemani because the antennae of the former 
have 16-17 segments (rarely 15) and the latter $15 \mathrm{seg}-$ ments. The labial palps of $A$. transcaspicus are 3 segmented (rarely 2 segmented) rather than 2 segmented as in $A$. colemani. In addition, those authors state that $A$. transcaspicus differs morphologically from $A$. colemani in having a lighter F1, lighter coloured posterior terga, more slender pterostigma, and a less triangular and shorter metacarpus.

The above shows that despite the intense effort to separate $A$. colemani from $A$. transcaspicus uncertainties remain because their morphological characteristics are very variable and overlap. Thus, $A$. colemani and $A$. transcaspicus are not readily distinguished from each other. Even more, recent data indicates that $A$. transcaspicus can exploit a wider host range than previously thought. In the laboratory, A. transcaspicus has been successfully reared on Aphis craccivora (Koch), Aphis fabae (Scopoli), A. gossypii, and M. persicae (Mackauer \& Starý, 1967; Starý, 1970; Takada, 2002; Li \& Mills, 2004; Starý, 2006; Wang \& Messing, 2006). Aphidius trancaspicus successfully attacks and parasitizes $M$. persicae infesting cabbage plants in field cages (Wang \& Messing, 2006).

In fact, in terms of systematics Aphidius is a difficult genus (Pungerl, 1983, 1986; Mescheloff \& Rosen, 1990). Some species within this genus are separated on the basis of their host aphids, despite being very difficult to distinguish morphologically, whilst laboratory experiments have shown that some of the morphological characters used for adult parasitoid identification can display considerable environmentally-induced variation (Pungerl, 1986). This approach was followed in the case of $A$. colemani and $A$. transcaspicus but has caused difficulties and given inconsistent results.

Molecular studies are becoming increasingly important in resolving taxonomic relationships in insects. Different genes are used to evaluate the genetic divergence of closely related species or populations (Caterino et al., 2000). The nuclear ribosomal repeat cistrons are widely used for phylogenetic studies of protistan, plant, and animal species. Nuclear RNA gene sequences have already proven valuable for studying higher taxonomic levels of insects (Pelendakis \& Solignac, 1993; Malafronte et al., 2007; Nelson et al., 2008). A region of these repeats more suitable for genus and species comparisons is the second Internal Trancribed Spacer region (ITS2), i.e., the one between the $5.8 \mathrm{~S}$ and $28 \mathrm{~S}$ RNA genes. The ITS2, a noncoding rapidly evolving region, has highly repetitive sequences that can differ among closely related populations, which have proven useful for comparing closely related insect species, subspecies, or populations (Collins \& Paskewitz, 1996; Fenton et al., 1998; Silva et al., 1999; Rokas et al., 2002; Rozenberg et al., 2006).

Studying genetic associations between closely related organisms is a topic that has recently attracted a large amount of attention. This is associated with the evolutionary concept concerning the genetic structure of populations and the process of speciation. This is especially important when using insect parasitoids in the biological control of aphid pests. This was recognized as a main ele- ment hindering the control of Hyalopterus spp. by $A$. transcaspicus in California (Lozier et al., 2008b).

The aim of the current study is to investigate the genetic association between $A$. colemani and A. transcaspicus. In particular two questions were addressed. Firstly, whether cross mating between individuals of $A$. colemani and $A$. transcaspicus is possible since cross mating indicates compatibility and thus, a close genetic relationship between two populations. Secondly, the genetic divergence between $A$. colemani and $A$. transcaspicus was determined using molecular methods. The combined use of these procedures provides a further contribution to the investigation of this taxonomic problem.

\section{MATERIAL AND METHODS}

\section{Experimental material}

A. colemani and A. transcaspicus were reared on $M$. persicae infesting pepper plants (cv. Vidi). The A. colemani culture was initiated by adults reared from $A$. gossypii mummies collected on Hibiscus syriacus L. (Malvaceae) and that of A. transcaspicus from Hyalopterus mummies collected on Prunus persica L. (Rosaceae) in Athens. The aphid species was named following Lozier et al. (2008a), with aphids of the genus Hyalopterus infesting peach most likely belonging to $H$. persikonus. $M$. persicae colonies were initiated from aphids collected from pepper plants growing on the Campus of the Agricultural University of Athens. Aphid colonies were maintained in wooden framed cages $80 \times 80 \times 70 \mathrm{~cm}$ in a glasshouse at an average temperature of $22.5 \pm 2.5^{\circ} \mathrm{C}$ (mean \pm S.D.) and under natural lighting.

Potted pepper plants infested with $M$. persicae were each covered with a plastic cage. Each cage $(11 \mathrm{~cm}$ in diameter and 30 $\mathrm{cm}$ high) was made of PVC ( $0.4 \mathrm{~mm}$ thick) with 2 openings of 9 $\times 9 \mathrm{~cm}$ each in the sides and the opening at the top covered with fine muslin for ventilation. Newly emerged parasitoids (15-20) (A. colemani or A. transcaspicus) were released into each cage and provided with food in the form of dilute drops of honey placed on the muslin covering the top of each cage. The cages were placed in a growth cabinet at $25 \pm 0.5^{\circ} \mathrm{C}, 65 \pm 5 \%$ R.H. and a $16 \mathrm{~L}: 8 \mathrm{D}$ photoperiod. The parasitoid cultures were maintained by transferring, by means of an insect aspirator, two day old parasitoids to another cage.

\section{Experimental procedure}

\section{Cross mating}

Mummified aphids were removed from the cultures and transferred individually to small plastic vials $(1 \mathrm{~cm}$ diameter $\times 4 \mathrm{~cm}$ height). The emerging parasitoids ( $<1$ day old) were sorted by sex. One female (A. colemani or A. transcaspicus) together with one male (A. transcaspicus or $A$. colemani) were placed in a plastic Petri dish $(9 \mathrm{~cm}$ in diameter and $1 \mathrm{~cm}$ in height, with a 3 $\mathrm{cm}$ in diameter opening in its lid covered with fine muslin, on which a droplet of honey was placed). After $24 \mathrm{~h}$, the female parasitoid was transferred to another Petri dish containing about 200 individuals of $M$. persicae (nymphs of all instars and adults) on an egg plant leaf. The leaf was on a layer of cotton wool, moistened with water, in the base of the dish. The dish was then placed in a growth cabinet at $25 \pm 0.5^{\circ} \mathrm{C}, 65 \pm 5 \%$ R.H. and a $16 \mathrm{~L}: 8 \mathrm{D}$ photoperiod. The parasitoid was removed from the dish after $24 \mathrm{~h}$. The leaf in each dish was replaced with a new one every other day and the aphids carefully transferred to the new leaf and reared until mummification. In total, there were thirty replicates ( 15 with a $A$. colemani female and 15 with a $A$. 
transcaspicus female). The number of parasitoids that emerged from the mummies was recorded for each female.

The number of antennal segments, the number of labial palps of the offspring with 15 antennal segments and the sex of the emerged offspring of each maternal female were recorded.

The fertility of one female offspring from each of the cross mated females was determined. The offspring of each cross mated female were kept in a dish for $24 \mathrm{~h}$ after emergence. Then one of the female offspring was transferred to a Petri dish containing approximately 200 nymphs and adults of $M$. persicae feeding on the leaf of an egg plant and its fertility recorded as described above. The sex of the offspring of each female was recorded.

The number of mummies and number of offspring resulting from the two crosses $(A$. colemani $i \times A$. transcaspicus $\widehat{0}$ and $A$. colemani $\sigma^{*} \times A$. transcaspicus $\uparrow$ ) were compared using one way ANOVA of logarithmically transformed data. The emergence rate and sex ratio were compared using one way ANOVA. The percentage of offspring assigned to A. colemani or A. transcaspicus in the two crosses was compared using a two-way ANOVA, with the species of the maternal female and the morphology of the offspring as factors. Similarly, the sex ratio of the offspring of each maternal female was tested for significance using a two-way ANOVA. Data on percentages were arcsine transformed prior to analysis. Means were separated using a Tukey-Kramer HSD test. Analyzes were done using the statistical package JMP (SAS Institute Inc., 2007)

\section{DNA extraction and amplification}

Five A. collemani females were reared from A. gossypii mummies collected from five H. syriacus plants and five $A$. transcaspicus females from $H$. persiconus mummies collected from five $P$. persica trees in Athens.

Total genomic DNA was extracted from each individual by mechanical trituration of the tissue (in buffer solution), followed by $1 \mathrm{~h}$ of chemical digestion with proteinase $\mathrm{K}$ and then a salt and ethanol precipitation. PCR products were amplified using the following ITS2 ribosomal primers (Porte \& Collins, 1991):

5.8SF: 5'-TGTGAACTGCAGGACACATGAAC and

28SR: 5'-ATGCTTAAATTTAGGGGGTA.

These primers anneal to highly conserved sequences in the 5.8S and 28S rDNA genes flanking the ITS2 region. The ITS2 PCR protocol was 40 cycles of $94^{\circ} \mathrm{C}$ for $45 \mathrm{~s}, 54^{\circ} \mathrm{C}$ for $45 \mathrm{~s}$ and $72^{\circ} \mathrm{C}$ for $60 \mathrm{~s}$. The PCR products were cloned in a Blue Script $\mathrm{KS}+$ plasmid vector (Agilent Technologies-Stratagene Products Division, La Jolla, CA, USA). Samples were sent for direct sequencing in both directions.

\section{Sequence alignment and phylogenetic analysis}

The boundaries of the ITS2 region were defined by comparison with previously determined Braconidae 5.8S and $28 \mathrm{~S}$ rDNA sequences submitted to the GenBank database at the US National Centre for Biotechnical Information (NCBI) (http://www.ncbi.nlm.nih.gov). Nucleotide sequences were aligned using the ClustalW program (http://www.ebi.ac.uk/clustalw/) under default parameters. Mean sequence divergence of ITS2 variants within and between each Aphidius population was estimated using PAUP* by uncorrected $\mathrm{P}$, which is the propor- tion of nucleotide sites differing between two compared sequences. The multiple alignment resulting from the ClustalW analysis was the input for BOXSHADE program (http://www.ch.embnet.org/software/BOX form.html), which was used to indicate residue similarity based on ITS2 sequences from various insects. All sequences were retrieved from GenBank. The retrieved sequences were aligned using ClustalX program and the multiple alignment method (Thompson et al., 1997). Gaps and missing data were excluded from the data analysis. The program package PHYLIP 3.6a2 (Felsenstein, 2001) was used for calculating trees. The tree was constructed using the Neighbour-Joining method.

\section{RESULTS}

Females of $A$. colemani used in the experiments had 15 (rarely 14) antennal segments and 2-segmented labial palps and males had 15 (rarely 16) antennal segments and 2 -segmented labial palps. Females of A. transcaspicus had 16 (rarely 15) antennal segments and 3-segmented labial palps and males 17-19 antennal segments and 3-segmented labial palps.

Cross mating occurred between $A$. colemani and $A$. transcaspicus as offspring (both females and males) were produced by all pairs. The results of the crossings between A.c. $q \times$ A.t. $\delta$ and A.c. $\delta \times$ A.t. $q$ are shown in Table 1. The mean number of mummies, mean number of offspring, emergence rate, and sex ratio were similar in the two crossings $\left(F_{1,28}=4.08, p<0.052 ; F_{1,28}=2.67, p>\right.$ $0.11 ; F_{1,28}=0.13, p>0.72$ and $F_{1,28}=0.07, p>0.79$, respectively).

The offspring were separated into three groups based on the morphological characters used to separate $A$. colemani and $A$. transcaspicus. The individuals with 15 antennal segments and 2-segmented labial palps were assigned to $A$. colemani. Those with more than 15 antennal segments were assigned to A. transcaspicus. Finally, individuals with 15-segmented antennae but 3 segmented labial palps were also grouped under A. transcaspicus, but in a different category following Kavallieratos \& Lykouressis (1999). The 3 categories are referred to as A.c., A.t.1, and A.t.2, respectively.

Crossing did not significantly affect the percentage of offspring assigned to A.c. or A.t. $\left(F_{1,56}=0.16, p>0.89\right)$. However, a significantly higher percentage of the offspring were assigned to A.t. than A.c. $\left(F_{1,56}=370.78, p<\right.$ $0.001)$. When A.c. mothers were used the percentage of the offspring assigned to A.c. was $31 \pm 3 \%$ and to A.t. 69 $\pm 4 \%$. In the case of A.t. mothers the percentages were 25 $\pm 1 \%$ and $75 \pm 2 \%$, respectively.

The percentage of the offspring assigned to each morphological type (A.c., A.t.1 and A.t.2), was not affected by the crossing $\left(F_{1,84}=0.82, p>0.36\right)$. However, there were significant differences among the percentages of

TABLE 1. Mean $( \pm \mathrm{SE})$ number of mummies, mean number of offspring, emergence rate, and sex ratio of offspring resulting from cross mating $A$. colemani and $A$. transcaspicus.

\begin{tabular}{ccccc}
\hline Crossing & Number of mummies $/ q$ & Number of offspring $/ q$ & Emergence rate & Sex ratio \\
\hline A.c. $\$ \times$ A.t. $\hat{0}$ & $61.6 \pm 2.8 \mathrm{a}$ & $49.4 \pm 2.5 \mathrm{a}$ & $0.69 \pm 0.02 \mathrm{a}$ & $0.54 \pm 0.01 \mathrm{a}$ \\
A.c. $\hat{\sigma} \times$ A.t. $q$ & $69.7 \pm 2.8 \mathrm{a}$ & $55.7 \pm 2.6 \mathrm{a}$ & $0.82 \pm 0.02 \mathrm{a}$ & $0.54 \pm 0.01 \mathrm{a}$ \\
\hline
\end{tabular}

Values within columns followed by the same lower case letter are not significantly different. 


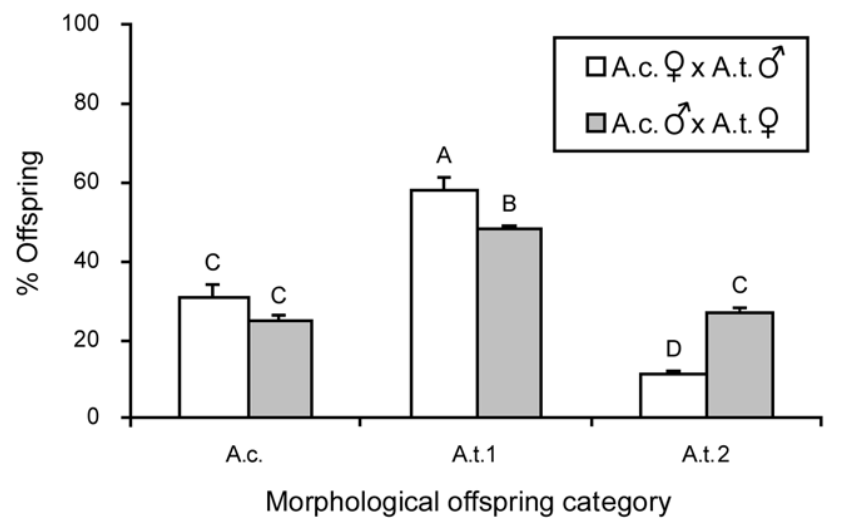

Fig. 1. Percentage (\%) (mean $\pm \mathrm{SE}$ ) of the offspring of each cross that were assigned to the different morphological categories. The individuals with 15 antennal segments and 2-segmented labial palps were assigned to A. colemani (A.c.) and those with more than 15 antennal segments were assigned to A. transcaspicus (A.t.1). Finally, individuals that had 15segmented antennae and 3 segmented labial palps were assigned A. transcaspicus (A.t.2). Columns topped with different letters indicate significantly different values.

offspring assigned to each of the three morphological types $\left(F_{2,84}=194.14, p<0.0001\right)$. The interaction between these two factors was significant $\left(F_{2,84}=35.63, p\right.$ $<0.0001)$. Significantly more of the offspring of A.c. $q \times$ A.t. $\delta$ were assigned to A.t. 1 than of the A.c. $\delta \times$ A.t. $q$ (Fig. 1). The percentages of the other categories (A.c. and A.t.2) were similar when the maternal female was $A$. transcaspicus. However, in the case of $A$. colemani females the percentage of the offspring assigned to A.t.2 was much reduced compared to A.c. (Fig. 1).
The sex ratio of the offspring within each morphological category is shown in Table 2. Statistical analyses revealed that the effect of the crossing, the effect of the morphological category of the offspring and their interaction were insignificant $\left(F_{1,84}=0.52 p>0.47 ; F_{2,84}=1.72\right.$, $p>0.18$ and $F_{2,84}=0.63, p>0.53$, respectively). The sex ratios ranged between $0.53 \pm 0.02$ and $0.59 \pm 0.05$.

All the female offspring used in fertility tests produced offspring. The average sex ratio of the offspring was 0.54 .

\section{Molecular analysis \\ Analysis of the 5.8S, ITS2, and 28S regions}

The primer pair (5.8SF and 28SR) amplified the ribosomal ITS2 of $A$. colemani and $A$. transcaspicus. Sequences were confirmed as ribosomal ITS2 by searching the GenBank database of the NCBI using BLAST protocol. Each sequence is available from GenBank (Accession number for A. colemani $=$ DQ504298 and for A. transcaspicus $=$ DQ504299).

Variability in the length of 5.8S-ITS2-28S was recorded both within and between populations of the two Aphidius examined. Lengths ranged from 739 to $745 \mathrm{bp}$ for the five individuals of $A$. colemani and from 639 to $645 \mathrm{bp}$ for the five of $A$. transcaspicus (Table 3).

Aligned ITS2 sequences of $A$. colemani (DQ504298) and $A$. transcaspicus (DQ504299), contained several inferred insertions or deletions (indels), the largest being 60 bp (Fig. 2). Three different regions of the rRNA gene can be distinguished. Region I ( $\sim 90 \mathrm{bp}$ in length) corresponds to the 5.8S rRNA coding sequence. ITS2 covers Region II ( $\sim 450$ bp in $A$. colemani and $\sim 385$ bp in $A$.

TABLE 2. The sex ratio (mean $\pm \mathrm{SE}$ ) of offspring of crosses between $A$. colemani and A. transcaspicus assigned to each morphological category. The offspring with 15 antennal segments and 2-segmented labial palps were assigned to A. colemani (A.c.) and those with more than 15 antennal segments to A. transcaspicus (A.t.1). Finally, offspring that had 15-segmented antennae and 3 segmented labial palps were assigned to $A$. transcaspicus (A.t.2).

\begin{tabular}{|c|c|c|c|}
\hline \multirow{2}{*}{ Crossing } & \multicolumn{3}{|c|}{ Morphological category of the offspring } \\
\hline & A.c. & A.t.1 & A.t.2 \\
\hline 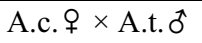 & $0.55 \pm 0.02 \mathrm{a}$ & $0.53 \pm 0.01 \mathrm{a}$ & $0.59 \pm 0.05 \mathrm{a}$ \\
\hline A.c. $\delta \times$ A.t. $q$ & $0.53 \pm 0.02 \mathrm{a}$ & $0.54 \pm 0.01 \mathrm{a}$ & $0.56 \pm 0.02 \mathrm{a}$ \\
\hline
\end{tabular}

Values followed by the same lower case letters are not significantly different.

TABLE 3. Sequence and length diversity of 5.8S-ITS2-28S variants from A. colemani and A. transcaspicus populations.

\begin{tabular}{ccccc}
\hline \multirow{2}{*}{ Species } & $\begin{array}{c}\text { GenBank } \\
\text { Accession Nos }\end{array}$ & $\begin{array}{c}\text { ITS2 length } \\
(\mathrm{bp})\end{array}$ & $\begin{array}{c}\text { GC content } \\
(\%)\end{array}$ & \begin{tabular}{c} 
Sequence divergence \\
\cline { 4 - 5 } A. colemani
\end{tabular} Detween individuals Between populations \\
\hline 1 & DQ504298 & 745 & 22.95 & \\
2 & FJ495547 & 744 & 22.85 & \\
3 & FJ495548 & 739 & 22.16 & 0.087 \\
4 & FJ495549 & 740 & 22.22 & \\
5 & FJ495550 & 743 & 22.88 & \\
A. transcaspicus & & & & \\
1 & DQ504299 & 682 & 23.49 & \\
2 & FJ495551 & 683 & 23.72 & \\
3 & FJ495552 & 679 & 23.31 & \\
4 & FJ495553 & 677 & 23.63 & \\
5 & FJ495554 & 684 & 23.68 & \\
\hline
\end{tabular}




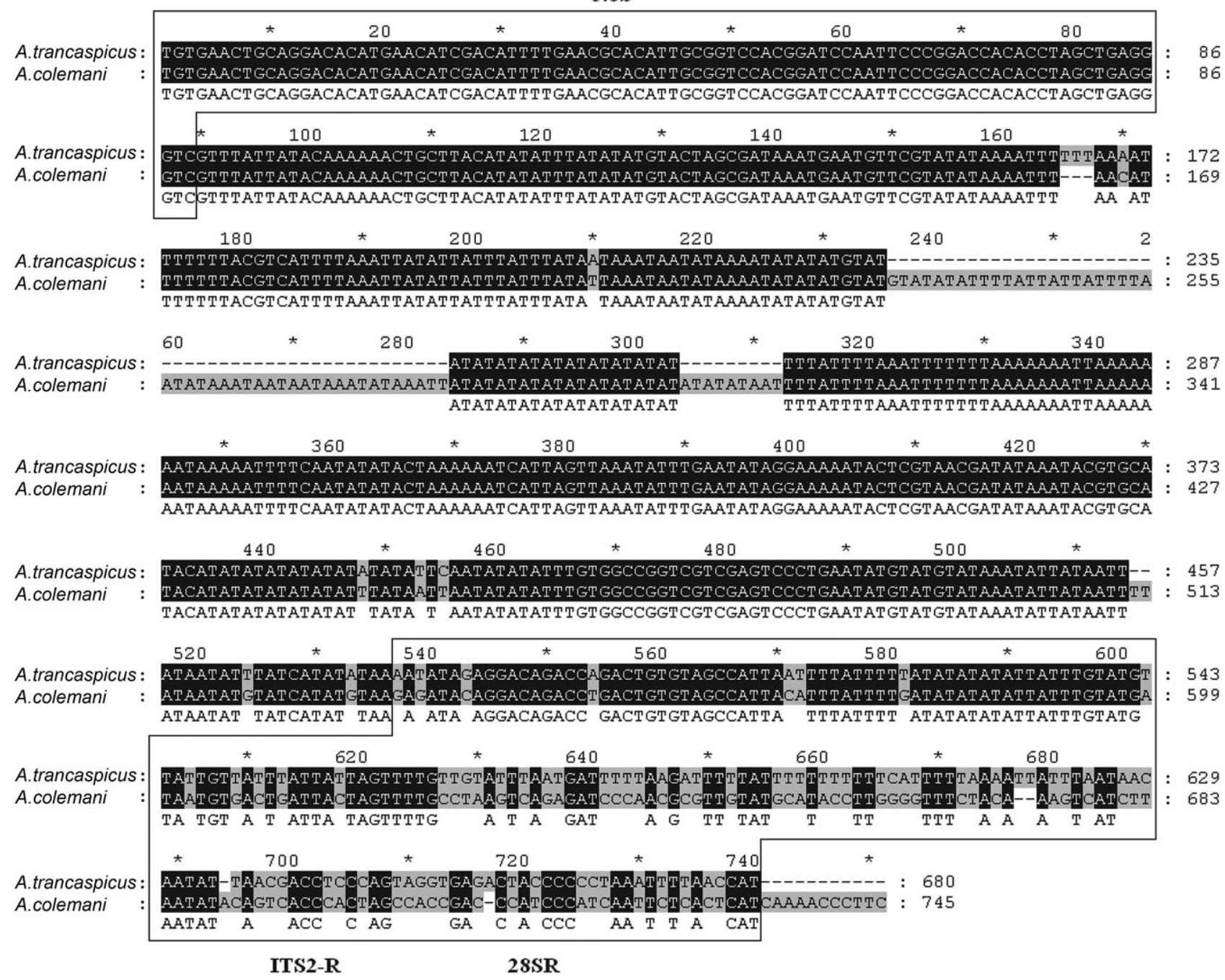

Fig. 2. Alignment of the sequences of the 5.8S, ITS2, and 28S regions of A. colemani (DQ504298) and A. transcaspicus (DQ504299). Identical nucleotides are shaded black. Dashes (-) indicate insertion/deletions.

transcaspicus). Region III covers a $\sim 205$ bp sequence at the 5' end of the 28S rRNA gene.

Mean sequence divergence of 5.8S-ITS2-28S within and between $A$. colemani and $A$. transcaspicus populations was estimated using PAUP* by uncorrected $P$ (Table 3). The mean GC content percentage of $A$. colemani was $22.8(\mathrm{SD}=0.19)$, whereas that of $A$. transcaspicus was 23.5 (SD $=0.21$ ). Sequence divergence recorded between individuals of $A$. colemani was 0.087 , the same as between $A$. transcaspicus. Sequence divergence (uncorrected $P$ ) between populations was 0.16 .

ITS2 phylogenetic analysis

Complete ITS2 sequences of the ribosomal DNA of six specimes/species of Hymenoptera (Braconidae) were determined using a BLAST search of GenBank. Namely: A. colemani (Greece) (DQ504298), 2-A colemani (USA) (EU561659), A. transcaspicus (DQ504299), Lysiphlebus testaceipes Cresson (Hymenoptera: Braconidae) (AY498555) and Leptopilina boulardi (Hymenoptera: Figitidae) (AY124568). ITS2 sequences were phylogenetically informative in separating Braconidae species (Fig. 3). Our results indicate that Aphidius populations ( $A$. colemani and A. transcaspicus) do not cluster in the same clade as Lysiphlebus, within the Aphidiinae.

\section{DISCUSSION}

According to our results, $A$. colemani and A. transcaspicus can interbreed. The $F_{1}$ generation consists of both females and males and the $F_{1}$ females are fertile. Thus the $A$. colemani and A. transcaspicus populations used in this study are compatible and genetically very similar.

Cross-mating is the main criterion for species separation (cryptic or complex species) (Mackauer, 1969; Starý et al., 1980). However, more recent research has shown that interspecific crosses may occur in the laboratory as in this artificial mating environment the ecological or behavioural barriers active in nature are not effective (Smith et al., 1993). In fact, neither the sterility or viability of offspring of cross matings are useful criteria of species status (Paterson, 1988). Even when interbreeding occurs the hybrid population might be viable only for a few generations or hybridization might result in a significant post mating fitness cost such as a reduction in offspring fecundity. According to the Haldane's rule, in haplodiploid 




0.1

Fig. 3. Phylogenetic bootstrap neighbour-joining tree (unrooted) built using CLUSTALX v1.8 default alignment of ITS2 genes of $A$. colemani and $A$. transcaspicus, and relevant ITS2 genes of other species. Bootstrap values for branches are shown (1000 replicates). The following abbreviations are used: Colemani: (A. colemani, DQ504298), 2-Colemani (A. colemani, EU561659), Transcaspicus (A. transcaspicus, DQ504299), Lysiphlebus (L. testaceipes, AY498555), and Leptopilina ( $L$. boulardi, AY124568) (as out group).

species, the fertility of $F_{2}$ males must be assessed since $F_{1}$ males are not hybrids (Koevoets \& Beukeboom, 2009). These shortcomings weaken the reliability of mating assays for identifying species, when done in the laboratory.

However, if the offspring of the crosses are classified according to their morphology, then most of them are $A$. trascaspicus (Fig. 1). In addition, 26\% of the offspring of A.t. $+\times$ A.c. 0 crosses and $9 \%$ of those of the A.c. $+\times$ A.t. $\hat{\sigma}$ crosses had 15 antennal segments and 3-segmented labial palps and were assigned to A. transcaspicus (A.t.2). According to Kavallieratos \& Lykouressis (1999) individuals of $A$. transcaspicus reared from Hyalopterus spp. collected from several areas in Greece, only very rarely have 15 antennal segments ( 1 female specimen in a total of 49 specimens collected). Therefore, a relatively high percentage of offspring of the crosses belong to a morphological type rarely occurring in nature. This indicates the potential for producing different morphological types, which could be used to evaluate the results of field surveys of variability in $A$. colemani and $A$. transcaspicus.

Based on morphological characters and cross mating it is difficult to determine conclusively the exact taxonomic association between A. colemani and A. transcaspicus. Therefore, a genetic approach was adopted based on quantifiable data obtained by characterization of rDNA sequences, including the second internal transcribed spacers, the inverting $5.8 \mathrm{~S}$ and adjacent portions of the $28 \mathrm{~S}$ coding regions. An advantage of this genomic target is that it includes highly conserved segments in the coding regions as well as hypervariable spacer sequences. The latter have repeatedly proved useful in distinguishing between taxonomic entities at and below the species level.

ITS2 sequences of $A$. trancaspicus were shorter than those of $A$. colemani and the difference in length was due to a deletion of $\sim 60 \mathrm{bp}$ at position 235 in the ITS2 fragment of $A$. trancaspicus (Fig. 2). The placement of indels was, in general, unambiguous and easily identifiable because they were sufficiently infrequent that they generally did not overlap (Lopez-Vaamonde et al., 2001). These consistent differences in length could be used to separate the two populations without the necessity of sequencing.

The ITS2 in the A. colemani and A. transcaspicus populations studied differed by $16 \%$. This level of divergence is quite high for the same species or sub-species. In similar studies it was difficult to confirm the species level when the variability in ITS2 sequence between populations is of this order (Onyabe \& Con, 1999; Romi et al., 2000; Lehr et al., 2005). Thus, we suggest that the DNA sequence divergence between $A$. colemani and $A$. transcaspicus populations might indicate a species-complex with different morphological and biological characters attacking different host aphids. Our results indicate that the $A$. colemani, A. transcaspicus-species complex is very complicated and requires further study. Future studies, including more nuclear and mtDNA genes, might further verify the species status of these two closely related aphid parasitoids.

\section{REFERENCES}

Bolckmans K. \& Tetteroo A. 2002: Biological pest control in eggplants in the Netherlands. IOBC/WPRS Bull. 25(1): 25-28.

Caterino M.S., Cho C. \& Sperling F.A.H. 2000: The current state of insect molecular systematics: a thriving tower of Babel. Annu. Rev. Entomol. 45: 1-54.

Collins F.H. \& Paskewitz S.M. 1996: A review of the use of ribosomal DNA (rDNA) to differentiate among cryptic Anopheles species. Insect. Mol. Biol. 5: 1-9.

Elenberg J., Enkegaard A., Vestergaard S. \& Jensen B. 2000: Biocontrol of pests on plant crops in Demark: Present status and future potential. Biocontr. Sci. Technol. 10: 703-716.

Felsenstein J. 2001: PHYLIP, Phylogeny Inference Package. Version 3.6a2. Department of Genetics, Univ. of Washington, Seattle.

Fenton B., Malloch G. \& Germa F. 1998: A study of variation in rDNA ITS region shows that two haplotypes coexist within a single aphid genome. Genome 41: 337-345.

Grasswitz T. \& ReEse B. 1998: Biology and host selection behaviour of the aphid hyperparasitoid Alloxysta victrix in association with the primary parasitoid Aphidius colemani and the host aphid Myzus persicae. Biol. Contr. 43: 261-271.

Kavallieratos N. \& LyKouressis D. 1999: Redescription of Aphidius trancaspicus Telenga and its distinction from Aphidius colemani Viereck (Hymenoptera: Braconidae). Boll. Lab. Entomol. Agr. F. Silvestri 55: 105-112.

Koevoets T. \& Beukeboom L.W. 2009: Genetics of postzygotic isolation and haldane's rule in haplodiploids. Heredity 102: $16-23$.

Lehr M.A., Kilpatrick C.W., Wilkerson R.C. \& Conn J.E. 2005: Cryptic species in the Anopheles (Nyssorhynchus) albitarsis (Diptera: Culicidae). Ann. Entomol. Soc. Am. 98: 908-917.

Li B. \& Mills N.J. 2004: The influence of temperature on size as an indicator of host quality for the development of a solitary koinobiont parasitoid. Entomol. Exp. Appl. 110: 249-256. Lopez-VaAmonde C., Rasplus J.Y., Weblen G.D. \& CoOK J.M. 2001: Molecular phylogenies of fig wasps: Partial coclado- 
genesis of pollinators and parasites. Mol. Plyl. Evol. 21: $55-71$.

Lozier J.D., Foottit R.G., Miller G.L., Mills N.J. \& Roderick G.K. 2008a: Molecular and morphological evaluation of the aphid genus Hyalopterus Koch (Insecta: Hemiptera: Aphididae), with a description of a new species. Zootaxa 1688: $1-19$.

Lozier J.D., Roderick G.K. \& MilLs N.J. 2008b: Evolutionarily significant units in natural enemies: Identifying regional populations of Aphidius transcaspicus (Hymenoptera: Braconidae) for use in biological control of mealy plum aphid. Biol. Control 46: 532-541.

MACKAUER M. 1969: Sexual behaviour and hybridization between three species of Aphidius Nees, parasitic on the pea aphid. Proc. Entomol. Soc. Wash. 71: 339-351.

MACKAUER M. \& STARÝ P. 1967: Index of Entomophagous Insects: World Aphidiidae. Le Francois, Paris, 195 pp.

Malafronte R.S., Marrelli M.T., Ramirez C.C., Nassar M.N. \& MARINotTI O. 2007: Intraspecific variation of second internal transcribed spacer of nuclear ribosomal DNA among populations of Anopheles (Kerteszia) cruzii (Diptera: Culicidae). J. Med. Entomol. 44: 538-542.

Mescheloff E. \& Rosen D. 1990: Biosystematic studies on the Aphidiidae of Israel (Hymenoptera: Ichneumonoidea). Israel J. Entomol. 24: 51-91.

Mills N.J. 2002: Prune Aphids: Fall Migration, Biological Control and Impact on Prune Production 2001. Prune Research Reports, California Prune Board, Sacramento, CA, pp. 18-30.

Nelson L.A., Wallman J.F. \& Dowton M. 2008: Identification of forensically important Chrysomya (Diptera: Calliphoridae) species using the second ribosomal internal transcribed spacer (ITS2). Forensic Sci. Int. 177(2-3): 238-247.

ONYABE D.Y. \& ConN J.E. 1999: Intragenomic heterogeneity of a ribosomal DNA spacer (ITS2) varies regionally in the Neotropical malaria vector Anopheles nuneztovari (Diptera: Culicidae). Insect Mol. Biol. 8: 435-442.

PAterson H.E.H. 1988: On defining species in terms of sterility: Problems and alternatives. Pacific Sci. 42: 65-71.

Pelendakis M. \& Solignac M. 1993: Molecular phylogeny of Drosophila based on ribosomal RNA sequences. J. Mol. Evol. 37: 525-543.

Pennacchio F. 1990: The Italian species of the genus Aphidius Nees (Hymenoptera: Braconidae: Aphidiinae). Boll. Lab. Entomol. Agr. F. Silvestri 46: 75-106.

Porte C.H. \& Colins F.H. 1991: Species-diagnostic differences in a ribosomal DNA internal transcriber spacer from the sibling species Snopheles freeborni and Anopheles hermis (Diptera: Culicidae). Am. J. Trop. Med. Hyg. 45: 271-279.

PUnGERL N.B. 1983: Variability in characters commonly used to distinguish Aphidius species (Hymenoptera: Aphidiidae). System. Entomol. 8: 425-430.

Pungerl N.B. 1986: Morphometric and electrophoretic study of Aphidius species (Hymenoptera: Aphidiidae) reared from a variety of aphid hosts. System. Entomol. 11: 327-354.

Rabasse J.M., Tardieux I. \& Pintureau B. 1985: Comparaison de deux populations française et brésilienne d'Aphidius colemani Viereck (Hymenoptera: Aphidiidae). Ann. Soc. Entomol. Fr. 21: 45-49.

Rokas A., Nylander J.A.A., Ronquist F. \& Stone G.N. 2002: A maximum-likelihood analysis of eight phylogenetic markers in gallwasp (Hymenoptera: Cynipidae): implications for insect phylogenetic studies. Mol. Phyl. Evol. 22: 206-219.

Romi D., Boccolini M., Di Luca G., La Rosa G. \& Marinucci M. 2000: Identification of the sibling species of the
Anopheles maculipennis complex by heteroduplex analysis. Insect Mol. 9: 509-551.

Rozenberg M., Kerdelhue C., Magnoux E., Turgeon J., Rasplus J. \& RoQues A. 2006: Molecular phylogeny and evolution of host plant use in conifer seed chalcids in the genus Megastigmus (Hymenoptera: Torymidae). System. Entomol. 31: $47-64$.

SAS Institute 2007: JMP version 7.0.1. SAS Institute Inc, Cary, NC.

Silva I.M., Honda J., van Kan F., Hu J., Neto L. \& Stouthamer R. 1999: Molecular differentiation of five Trichogramma species occurring in Portugal. Biol. Contr. 16: 177-184.

Smith D.C., Lyons S.A. \& Berlocher S.H. 1993: Production and electrophoretic variation of $\mathrm{F} 1$ hybrids between sibling species Rhagoletis pomonella and R. corniva. Entomol. Exp. Appl. 69: 209-213.

STARÝ P. 1964: Intergrated control problems of citrus and peach aphid pests in Italy orhards. Entomophaga 9: 147-152.

STARÝ P. 1965: Aphidiid parasites of aphids in the USSR (Hymenoptera: Aphidiidae). Acta Faun. Entomol. Mus. Nat. Pragae 10: 187-227.

Starý P. 1966: Aphid Parasites of Czechoslovakia: A Review of the Czechoslovak Aphidiidae (Hymenoptera). Czechoslovak Academy of Sciences, Prague, pp. 149.

Starý P. 1970: Biology of Aphid Parasites with Respect to Integrated Control. Dr. W. Junk, The Hague, 656 pp.

STARÝ P. 1975: Aphidius colemani Viereck: its taxonomy, distribution and host range (Hymenoptera: Aphidiidae). Acta Entomol. Bohemoslov. 72: 156-163.

StARÝ P. 1988: Aphidiidae. In Minks A.K. \& Harrewijn P. (eds): Aphids, Their Biology, Natural Enemies and Control. Vol. B. Elsevier, Amsterdam, pp. 171-184.

StarÝ P. 2006: Aphid Parasitoids of the Czech Republic (Hymenoptera: Braconidae: Aphidiinae). Academia, Praha, $430 \mathrm{pp}$.

Starý P., Gonzalez D. \& Hall J.C. 1980: Aphidius eadyi sp. n. (Hymenoptera: Aphidiidae), a widely distributed parasitoid of the pea aphid, Acyrthosiphon pisum (Harris) in the Palaearctic. Entomol. Scand. 11: 473-480.

TAKADA H. 1998: A review of Aphidius colemani (Hymenoptera: Braconidae: Aphidiinae) and closely related species indigenous to Japan. Appl. Entomol. Zool. 33: 59-66.

TAKADA H. 2002: Parasitoids (Hymenoptera: Braconidae, Aphidiinae; Aphelinidae) of four principal pest aphids (Homoptera: Aphididae) on greenhouse vegetable crops in Japan. Appl. Entomol. Zool. 37: 237-249.

TARDRIEUX I. \& RABASSE J. 1988: Induction of a thelytokous reproduction in the Aphidius colemani (Hym., Aphidiidae) complex. J. Appl. Entomol. 106: 58-61.

Thompson J.D., Gibson T.J., Plewniak F., Jeanmougin F. \& HigGINS D.G. 1997: The ClustalX windows interface: flexible strategies for multiple sequence alignment aided by quality analysis tools. Nucl. Acids Res. 24: 4876-4882.

VAN LENTEREN J.C. 2003: Commercial availability of biological control agents. In van Lenteren J.C. (ed.). Quality Control and Production of Biological Control Agents: Theory and Testing Procedures. CABI, Cambridge, pp. 167-179.

Van Schelt J., Douma J.B. \& Raveneberg W.J. 1990: Recent developments in the control of aphids in sweet pepper and cucumber. IOBC/WPRS Bull. 13(5): 190-193.

WAng X. \& Messing R. 2006: Potential host range of newly introduced aphid parasitoid Aphidius transcaspicus (Hymenoptera: Braconidae) in Hawaii. Proc. Hawai. Entomol. Soc. 38: $81-86$. 
